\title{
Erratum to: Smartphone versus knee ligament arthrometer when size does not matter
}

\author{
Andrea Ferretti • Luigi Valeo • Daniele Mazza • \\ Luca Muliere • Paolo Iorio • Giovanni Giovannetti • \\ Fabio Conteduca $\cdot$ Raffaele Iorio
}

Published online: 6 August 2014

(C) SICOT aisbl 2014

Erratum to: International Orthopaedics (SICOT)

DOI 10.1007/s00264-014-2432-9

The original version of this article inadvertently contained mistakes because the author's names were listed by their first names and not by surname.

The correct presentation is given in this erratum publication.

The online version of the original article can be found at http://dx.doi.org/ $10.1007 / \mathrm{s} 00264-014-2432-9$.

A. Ferretti $\cdot$ L. Valeo $\cdot$ D. Mazza $(\triangle) \cdot$ L. Muliere $\cdot$ P. Iorio $\cdot$

G. Giovannetti $\cdot$ F. Conteduca $\cdot$ R. Iorio

Orthopaedic Unit and "Kirk Kilgour" Sports Injury Centre S. Andrea

Hospital, University of Rome, Via Grottarossa 1035, Rome (RM),

Sapienza, Italy

e-mail: daniele.mazza@hotmail.it 